ARTICLE

\title{
Scalable, highly stable Si-based metal-insulator- semiconductor photoanodes for water oxidation fabricated using thin-film reactions and electrodeposition
}

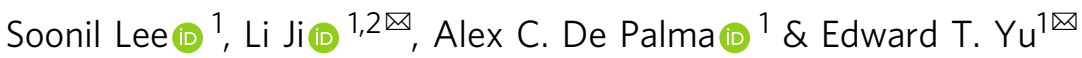

Metal-insulator-semiconductor (MIS) structures are widely used in Si-based solar watersplitting photoelectrodes to protect the Si layer from corrosion. Typically, there is a tradeoff between efficiency and stability when optimizing insulator thickness. Moreover, lithographic patterning is often required for fabricating MIS photoelectrodes. In this study, we demonstrate improved Si-based MIS photoanodes with thick insulating layers fabricated using thinfilm reactions to create localized conduction paths through the insulator and electrodeposition to form metal catalyst islands. These fabrication approaches are low-cost and highly scalable, and yield MIS photoanodes with low onset potential, high saturation current density, and excellent stability. By combining this approach with a $\mathrm{p}^{+} \mathrm{n}-\mathrm{Si}$ buried junction, further improved oxygen evolution reaction (OER) performance is achieved with an onset potential of $0.7 \mathrm{~V}$ versus reversible hydrogen electrode ( $\mathrm{RHE}$ ) and saturation current density of $32 \mathrm{~mA} / \mathrm{cm}^{2}$ under simulated AM1.5G illumination. Moreover, in stability testing in $1 \mathrm{M}$ $\mathrm{KOH}$ aqueous solution, a constant photocurrent density of $\sim 22 \mathrm{~mA} / \mathrm{cm}^{2}$ is maintained at 1.3 $\checkmark$ versus RHE for 7 days.

\footnotetext{
${ }^{1}$ Microelectronics Research Center, University of Texas, Austin, TX, USA. ${ }^{2}$ State Key Laboratory of ASIC and System, School of Microelectronics, Fudan University, Shanghai, China. ${ }^{凶}$ email: lji@fudan.edu.cn; ety@ece.utexas.edu
} 
P hotoelectrochemical (PEC) water splitting is a promising technology for converting solar energy into clean and storable chemical energy. In PEC cells, semiconductors play a key role in absorbing photons from the light source to create mobile charge carriers. Various semiconductor materials have been studied for the high-performance PEC cells, including metal oxides $^{1-4}$, nitrides ${ }^{5,6}, \mathrm{Si}^{7-17}$, III-V compound semiconductor materials ${ }^{18-20}$, and others ${ }^{21,22}$. Among these, Si-based photoelectrodes have attracted substantial interest due to silicon's moderate bandgap $(1.12 \mathrm{eV})$, high charge mobility and diffusion lengths, and well-established technological infrastructure ${ }^{23}$. However, Si-based photoanodes for the oxygen evolution reaction (OER) remain challenging to engineer due to the complex fourelectron reaction mechanism which requires a large overpotential, and poor chemical stability in alkaline solutions. To improve the OER performance of Si-based photoanodes, metal-insulatorsemiconductor (MIS) structures have been widely used for Sibased photoanodes due to their high efficiency and improved stability $9-11,14-16$. An efficient metal catalyst at the surface improves the reaction kinetics of photoanodes, reducing the overpotential for OER ${ }^{17,24-26}$. Corrosion of $\mathrm{Si}$ in aqueous electrolytes is suppressed in MIS photoelectrode structures by protecting the Si surface using thin layers of insulators such as $\mathrm{TiO}_{2}{ }^{13,27,28}, \mathrm{NiO}_{X}{ }^{9,11,12}, \mathrm{SrTiO}_{3}{ }^{8}, \mathrm{SiN}_{X}{ }^{29}$, and $\mathrm{SiO}_{X}{ }^{9-11,14-16}$.

For a Si-based MIS photoanode, minority carriers are generated by illumination of the semiconductor and, typically, extracted to the metal layer by tunneling through the insulator, as shown in Fig. 1a. The tunneling current density decreases exponentially with increasing insulator layer thickness so that, with few exceptions ${ }^{10}$, ultrathin insulators under $5 \mathrm{~nm}$ are needed for efficient MIS photoanodes ${ }^{30}$. However, it has also been reported that MIS photoelectrodes with thin protective insulator layers can be susceptible to corrosion of the semiconductor in alkaline solutions, so that insulator layer thicknesses above $50 \mathrm{~nm}$ are required for longterm stability in alkaline solutions ${ }^{31,32}$. Due to this tradeoff between efficiency and stability, optimizing the insulating layer thickness is key to the OER performance of MIS photoanodes.
Our previous work demonstrated a new approach to increasing the effective conductivity of a thick insulating layer in MIS photoelectrodes by electrically inducing the localized dielectric breakdown of the insulating region beneath metal catalyst islands ${ }^{10}$. Since the breakdown process resulted in the formation of localized conductive paths through the thick oxide layer, photogenerated minority carriers are easily transported via the conductive path instead of by tunneling. Using this approach, improved photocurrents were observed with good long-term stability due to the thick insulating layers. However, this method requires complex and time-consuming processing techniques for the formation of localized breakdown paths, along with lithographic patterning of the top metal layer. Recently, Loget et al. ${ }^{11}$ and Zhao et al. ${ }^{12}$ reported on the deposition of $\mathrm{Ni}$ catalysts for the metal layer of MIS photoanodes using electrodeposition and electroless deposition, respectively. These methods yielded welldefined Ni deposition for the MIS photoanode and enabled efficient OER performance without using complex lithographic techniques. However, stability in high $\mathrm{pH}$ aqueous solutions was limited to $40 \mathrm{~h}$ or considerably less, potentially due to the absence of an insulating protective layer of sufficient quality and thickness.

Herein, we demonstrate a low-cost and highly scalable method for producing high-performance and very stable Si-based MIS photoanodes by exploiting a thin-film reaction of $\mathrm{Al}$ through an insulating oxide layer followed by $\mathrm{Ni}$ electrodeposition, and not requiring any lithographic patterning. The thin-film reaction of $\mathrm{Al}$ with $\mathrm{SiO}_{2}$ or $\mathrm{Si}$, leading to localized penetration of $\mathrm{Al}$ "spikes" into the underlying material, has been studied extensively since it can cause an electrical short in silicon pn-junction structures with $\mathrm{Al}$ contact metallization. Al spiking can also occur through an insulating $\mathrm{SiO}_{2}$ layer, and has been exploited to form Ohmic contacts through an oxide passivation layer on $\mathrm{Si}^{33,34}$. In an MIS photoelectrode structure with $\mathrm{Al}$ as the metal layer, annealing of the $\mathrm{Al} / \mathrm{SiO}_{2} / \mathrm{Si}$ structure above $300{ }^{\circ} \mathrm{C}$ causes $\mathrm{Al}$ to penetrate the underlying $\mathrm{SiO}_{2}$ and induces the formation of localized metal spikes in the MIS structure. As shown in Fig. 1b, each metal spike a

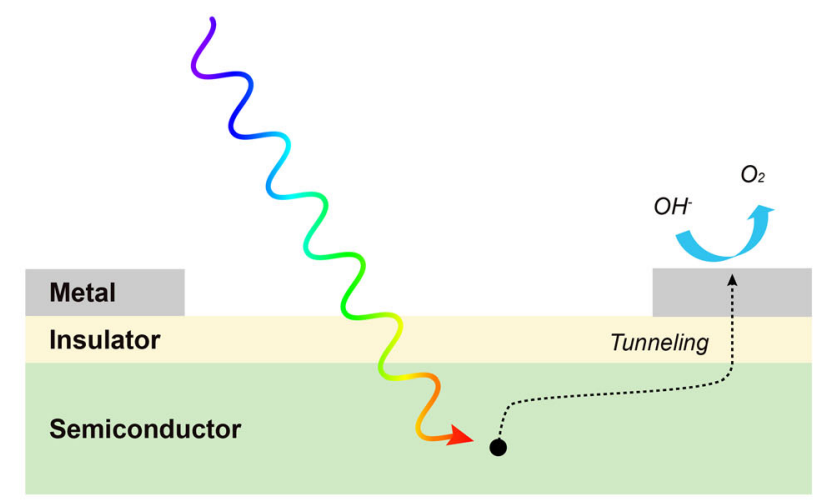

b

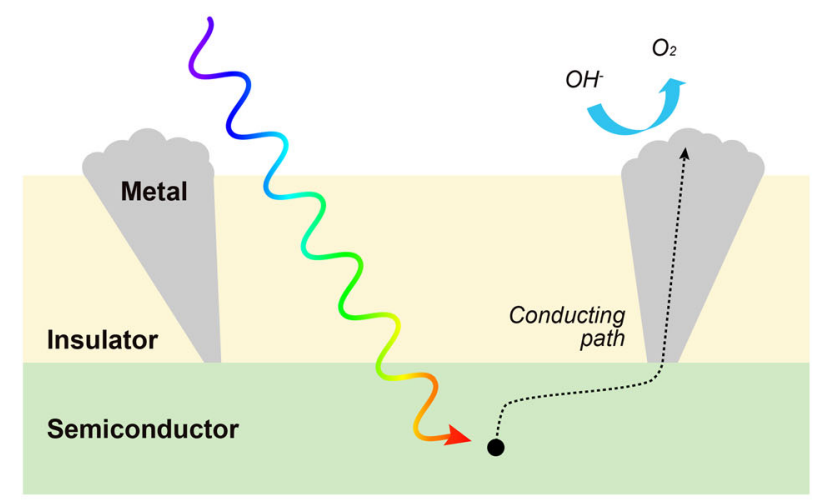

C

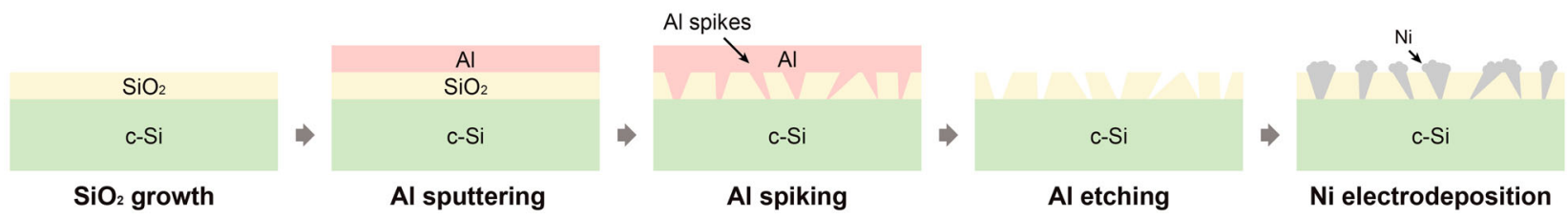

Fig. 1 Schematics of metal-insulator-semiconductor photoanodes. a Schematic illustration of conventional approach for photogenerated carrier transport, via tunneling, across thin electrically insulating layer in MIS photoelectrode. b Schematic illustration of localized metallic conduction paths through a thick electrically insulating layer, enabling the use of much thick insulators that provide high stability in an MIS photoelectrode. c Schematic illustration of a highly scalable, nonlithographic fabrication process for realizing structure shown in $\mathbf{b}$. 
provides a local conductive path through the thick $\mathrm{SiO}_{2}$ layer. Typical spike densities are $\sim 10^{8}-10^{9} \mathrm{~cm}^{-2}$, enabling a very efficient collection of photogenerated carriers. The surrounding regions of oxide remain electrically insulating and retain their protective functionality. In this work, after the formation of localized $\mathrm{Al}$ spikes through the $\mathrm{SiO}_{2}$ layer, the $\mathrm{Al}$ is etched and replaced, via electrodeposition, by $\mathrm{Ni}$, which serves as the OER catalyst. During the electrodeposition process, Ni covers the exposed Si surface resulting in the growth of dispersed Ni nanoislands on the $\mathrm{SiO}_{2}$ surface at the corresponding locations. The remaining exposed thick $\mathrm{SiO}_{2}$ and the electrodeposited $\mathrm{Ni}$ have excellent corrosion resistance in alkaline aqueous solutions. This process results in the formation of Si-based MIS photoanodes with high efficiency, good long-term stability, low cost, and high manufacturability without using any complex and costly lithographic patterning techniques.

\section{Results and discussion}

Al thin-film reaction on Si-based MIS photoanode. Figure 1c shows the fabrication process for a Si MIS photoanode using the $\mathrm{Al} / \mathrm{SiO}_{2}$ thin-film reaction to form localized $\mathrm{Al}$ spikes. As shown schematically in Fig. 1b, to help ensure long-term stability of the photoanode, $90 \mathrm{~nm}$ thick $\mathrm{SiO}_{2}$ layers were formed by thermal oxidation to serve as the insulator of the MIS structure ${ }^{31}$. A 90 $\mathrm{nm}$ thick $\mathrm{SiO}_{2}$ layer also provides low optical surface reflectance in water in the 400-900 $\mathrm{nm}$ wavelength range (Supplementary Fig. 1). To form localized $\mathrm{Al}$ paths through the $\mathrm{SiO}_{2}$ insulating layer, $100 \mathrm{~nm} \mathrm{Al}$ was deposited by DC sputtering, followed by annealing. During the annealing process, the $\mathrm{Al}$ penetrates locally through the $\mathrm{SiO}_{2}$ layer and contacts the $\mathrm{Si}$ substrate. Since this Al spiking thin-film reaction occurs in localized areas across the whole surface, an array of localized contacts between the metal and semiconductor layers is formed within the $\mathrm{Al} / \mathrm{SiO}_{2} / \mathrm{Si}$ structure. Since the $\mathrm{Al}$ film is easily corroded in solution, however, it is not suitable for the metal layer of an MIS photoanode. Therefore, the $\mathrm{Al}$ was replaced by $\mathrm{Ni}$, which shows good stability and acts as an OER catalyst. The Al layer was first etched by $\mathrm{Al}$ etchant, leaving exposed the unreacted $\mathrm{SiO}_{2}$ surface and the $\mathrm{Si}$ surface underlying the areas where the spiking $\mathrm{Al}$ reaction occurred. After etching the $\mathrm{Al}, \mathrm{Ni}$ was deposited on the resulting surface by electrodeposition. During this process, Ni fills the exposed $\mathrm{Si}$ areas first, since higher electric fields are present at the exposed $\mathrm{Si}$ surface, and then forms $\mathrm{Ni}$ nano-islands. As a result, a $\mathrm{Ni} / \mathrm{SiO}_{2} / \mathrm{Si}$ MIS photoanode with localized Ni conductive paths through the oxide can be fabricated using the $\mathrm{Al}$ thin-film reaction followed by etching and Ni electrodeposition.

To optimize the $\mathrm{Al}$ thin-film reaction and spiking process, a series of $\mathrm{Al} / \mathrm{SiO}_{2} / \mathrm{Si} / \mathrm{SiO}_{2} / \mathrm{Al}$ samples were prepared by $\mathrm{SiO}_{2}$ growth and $\mathrm{Al}$ deposition on both sides of $\mathrm{Si}$ substrates, and their series resistance from top to bottom (top-bottom resistance) was measured before and after different annealing processes (Fig. 2a and Supplementary Fig. 2). It has been reported that, in an $\mathrm{Al} /$ $\mathrm{SiO}_{2} / \mathrm{Si}$ structure, $\mathrm{Al}$ reduces the underlying $\mathrm{SiO}_{2}$ layer and penetrates to the Si layer during annealing, the phenomenon referred to as $\mathrm{Al}$ spiking ${ }^{33-35}$. The formation of $\mathrm{Al}$ spikes requires around $2.56 \mathrm{eV}$ of activation energy for the $\mathrm{SiO}_{2}$ reduction process, and can occur at temperature above $300{ }^{\circ} \mathrm{C}^{35}$. The topbottom resistance changes were measured for annealing temperatures of $450-600^{\circ} \mathrm{C}$ and durations of $0-24 \mathrm{~h}$ as shown in Fig. 2a. Before the annealing process, the top-bottom resistances of the $\mathrm{Al} / \mathrm{SiO}_{2} / \mathrm{Si} / \mathrm{SiO}_{2} / \mathrm{Al}$ substrates were relatively high (20-30 $\Omega \mathrm{cm}^{2}$ ) due to the thick $\mathrm{SiO}_{2}$ insulating layers. In the red-shaded region of Fig. 2a, the high resistance was maintained for the first several hours for all annealing temperatures. However, as the temperature and duration of annealing increased, there was a sharp transition in resistance to $\sim 10 \%$ of its initial value (green region in Fig. 2a). After this transition, the resistance reaches $\sim 0.5 \%$ of its initial value (blue region in Fig. 2a) for a longer annealing time and/or higher annealing temperature. During the annealing process, $\mathrm{Al}$ penetrates locally through the $\mathrm{SiO}_{2}$ layers and reaches the underlying $\mathrm{Si}$ substrate, forming a metallic path and Ohmic contact between the $\mathrm{Al}$ and $\mathrm{Si}$ layers as shown in Fig. 2b. The formation of these structures causes an abrupt drop in top-bottom resistance at the transition points. Before the annealing process, the $\mathrm{Al}$ layer exhibits uniform morphology on the surface (Fig. 2c). After annealing of an $\mathrm{Al} / \mathrm{SiO}_{2} / \mathrm{Si}$ structure at $550^{\circ} \mathrm{C}$ for $24 \mathrm{~h}$, localized $\mathrm{Al}$ spikes were observed on the surface (Fig. 2d). After etching the $\mathrm{Al}$ layer from the $\mathrm{Al} / \mathrm{SiO}_{2} / \mathrm{Si}$ substrate, $\mathrm{SiO}_{2} / \mathrm{Si}$ surfaces before and after the annealing process were characterized again using plan-view scanning electron microscopy (SEM). Without any annealing, a uniform $\mathrm{SiO}_{2}$ surface was observed after the removal of the Al layer. After annealing and subsequent etching away of the $\mathrm{Al}$, random localized voids in the $\mathrm{SiO}_{2}$ layer, corresponding to areas where Al spiking occurred, were observed on the Al-etched $\mathrm{SiO}_{2} / \mathrm{Si}$ surface with $\sim 1.7 \%$ surface coverage by the void regions and with void diameters ranging from 10 to $130 \mathrm{~nm}$, corresponding to an areal density of voids of $\sim 2-8 \times 10^{8} / \mathrm{cm}^{2}$ for annealing temperatures of $450-600{ }^{\circ} \mathrm{C}$ (Supplementary Fig. 3). The density and size distribution of voids do not appear to depend strongly on annealing temperature or duration (Supplementary Fig. 3). AFM imaging of $\mathrm{SiO}_{2} / \mathrm{Si}$ surfaces after annealing and $\mathrm{Al}$ etching confirmed that the $\mathrm{Al}$ spikes penetrated completely through the $\mathrm{SiO}_{2}$ layer but not into the underlying $\mathrm{Si}$, and that the regions between the spikes remained very close to their original thickness, but with slightly increased surface roughness (Supplementary Fig. 6). The corresponding average distance between adjacent voids is considerably smaller than the typical diffusion length of minority carriers in $\mathrm{c}-\mathrm{Si}$, enabling the efficient collection of photogenerated holes during photoanode operation. This is a natural consequence of the nature of the Al spiking reaction into thermally grown $\mathrm{SiO}_{2}$, and enables the desired spatial distribution of conductive paths to metal catalyst layers to be realized without deliberate lithographic patterning.

Electrodeposition of Ni catalyst. For MIS photoanodes, the metal catalyst layer is essential in enhancing the overall reaction rate, reducing the onset voltage, and increasing the current density. $\mathrm{Ni}$ is frequently used as an OER catalyst due to its good electrical conductivity, efficient catalytic effect, and corrosion resistance at high $\mathrm{pH}^{11}$. In this study, $\mathrm{Ni}$ was incorporated as a catalyst for the photoanode using electrodeposition, following the formation of localized voids in the $\mathrm{SiO}_{2}$ protective layer by $\mathrm{Al}$ thin-film reaction and etching (Supplementary Fig. 4). Other catalyst materials could readily be employed using this approach. The morphology of Ni deposited on the surface can be controlled by varying the applied bias and deposition time for electrodeposition. When a negative bias is applied to the substrate, $\mathrm{Ni}$ deposition begins by filling the voids in the $\mathrm{SiO}_{2}$ layer, since the highest electric fields are present at the interface between the aqueous solution and the exposed $\mathrm{Si}$ surface. Ni is nucleated at these locations and eventually forms larger islands on the surface. Figure $3 \mathrm{a}-\mathrm{c}$ shows SEM images of $\mathrm{Ni}$ electrodeposited on the $\mathrm{SiO}_{2} / \mathrm{Si}$ surface for different electrodeposition conditions. When low electrodeposition bias $(-0.5 \mathrm{~V})$ was applied, $\mathrm{Ni}$ nano-islands were observed on the surface and their number and size increased with increasing applied bias and electrodeposition time. Shown in Fig. $3 \mathrm{~d}$ is a box plot of the diameters of the Ni nano-islands after $80 \mathrm{~min}$ of electrodeposition at applied bias voltages of $-0.5,-1.0$, and $-2.0 \mathrm{~V}$. The mean diameter of the Ni nano-islands increased 
a

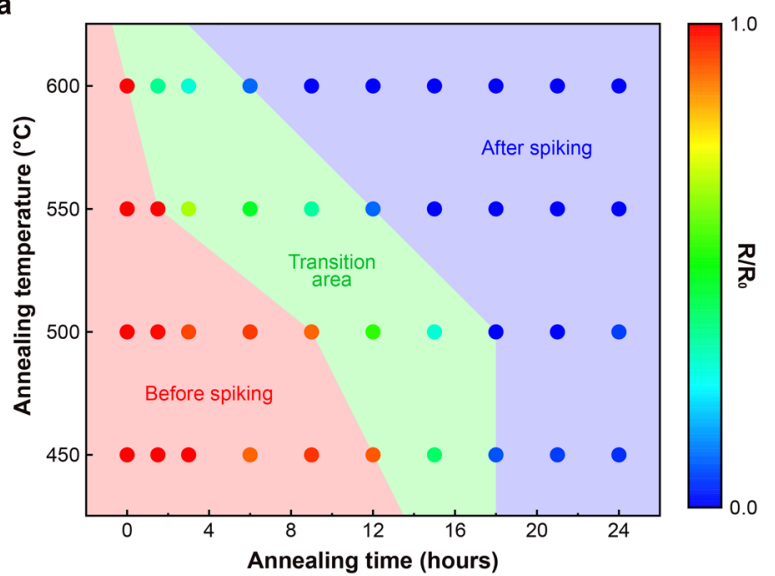

b

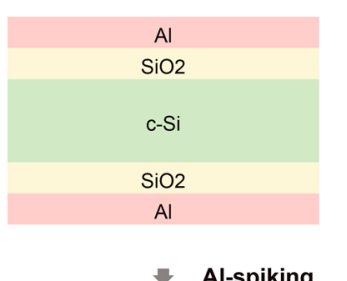

Al-spiking

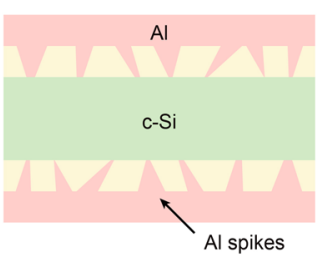

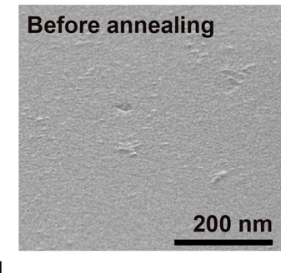

.

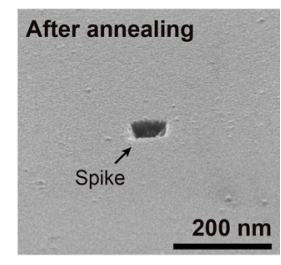

Fig. 2 Resistance changes after Al spiking. a Electrical resistance of $\mathrm{Al} / \mathrm{SiO}_{2} / \mathrm{Si} / \mathrm{SiO}_{2} / \mathrm{Al}$ structure as a function of annealing temperature and duration. $\mathbf{b}$ Schematic illustration of sample structure evolution upon annealing to induce thin-film reaction between $\mathrm{Al}$ and $\mathrm{SiO}_{2}$ to form $\mathrm{Al}$ "spikes" penetrating the $\mathrm{SiO}_{2}$ layers. c, d Scanning electron micrographs of $\mathrm{SiO}_{2}$ surface, before and after annealing. e Scanning electron micrographs of $\mathrm{SiO}_{2}$ surface before annealing and after $24 \mathrm{~h}$ annealing at temperatures of $450-600^{\circ} \mathrm{C}$.

a

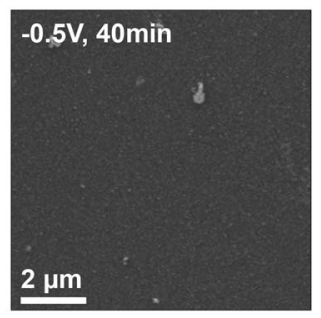

b

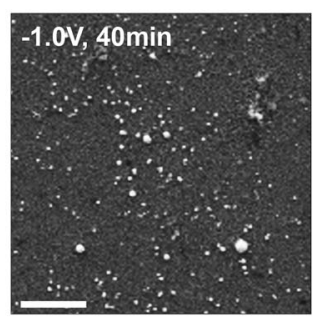

C

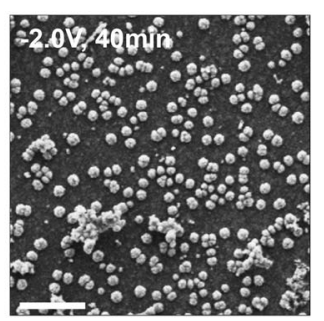

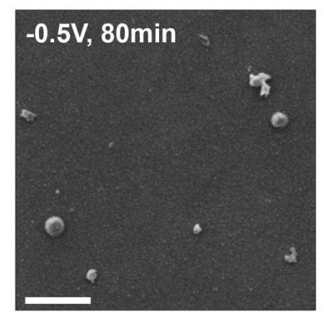
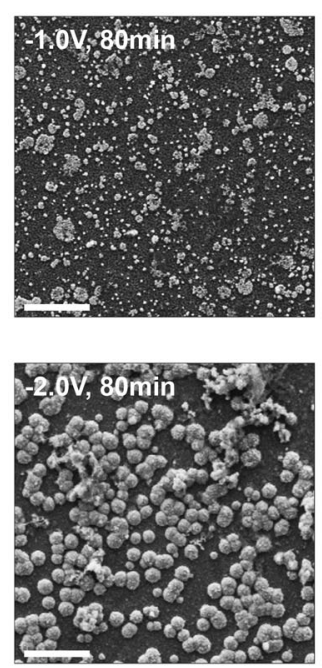
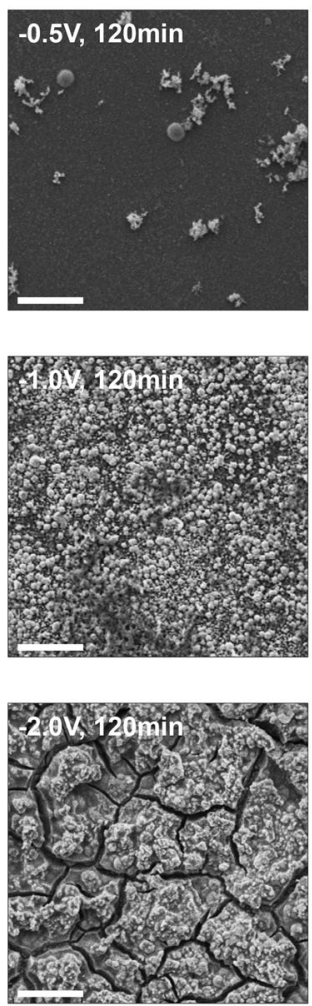

d

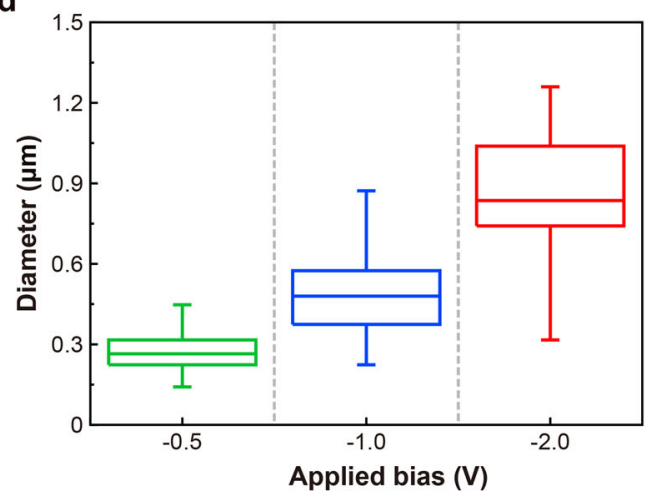

e

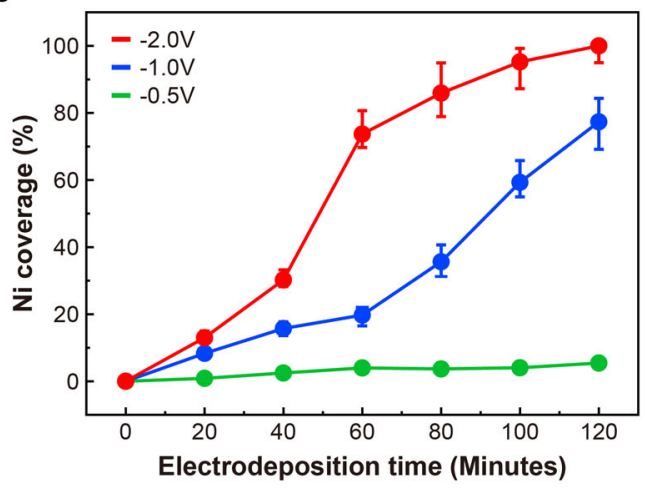

Fig. 3 Characterization of $\mathbf{N i}$ electrodeposition. a-c SEM images of Ni electrodeposited into voids created within a $90 \mathrm{~nm} \mathrm{SiO}_{2}$ layer on an $\mathrm{n}$-type $\mathrm{Si}$ substrate via thin-film reaction with Al, for electrodeposition bias voltages of -0.5 (a), -1.0 (b), and $-2.0 \mathrm{~V}$ (c) and for the electrodeposition times of 40 , 80 , and $120 \mathrm{~min}$. All inset scale bars are $2 \mu \mathrm{m}$. $\mathbf{d}$ The size distribution of $\mathrm{Ni}$ nano-islands on the $\mathrm{SiO}_{2} / \mathrm{Si}$ surface after 60 min electrodeposition at applied bias voltages of $-0.5,-1.0$, and $-2.0 \mathrm{~V}$. e Ni coverage on the $\mathrm{SiO}_{2} / \mathrm{Si}$ surface as a function of electrodeposition time, for electrodeposition bias voltages of $-0.5,-1.0$, and $-2.0 \mathrm{~V}$.

from 0.26 to $0.83 \mu \mathrm{m}$ as the applied bias increased from -0.5 to $-2.0 \mathrm{~V}$. In addition, a broader diameter distribution was observed for the $\mathrm{Ni}$ nano-islands deposited at more negative applied bias. Growth and eventually coalescence of the Ni nano-islands occurs with increasing Ni coverage. Figure $3 \mathrm{e}$ shows the Ni coverage on the $\mathrm{SiO}_{2}$ layer as a function of electrodeposition time. At $-0.5 \mathrm{~V}$ applied bias, the Ni coverage increased very slowly, not exceeding $5 \%$ after 120 min electrodeposition time. When higher bias was applied, clearer increases in $\mathrm{Ni}$ coverage were observed with increasing electrodeposition time and, after $120 \mathrm{~min}, \sim 78 \%$ and $\sim 100 \% \mathrm{Ni}$ coverage was obtained at -1.0 and $-2.0 \mathrm{~V}$, respectively. As shown in Fig. 3c, after $120 \mathrm{~min}$ electrodeposition at $-2.0 \mathrm{~V}$, the $\mathrm{Ni}$ aggregates form a continuous $\mathrm{Ni}$ film with a thickness of $\sim 0.3 \mu \mathrm{m}$ that covers almost the whole surface of the $\mathrm{SiO}_{2}$ layer. Cross-sectional SEM imaging and energy-dispersive $\mathrm{X}$-ray spectroscopy (EDS) measurements confirmed that the $\mathrm{Ni}$ 
a

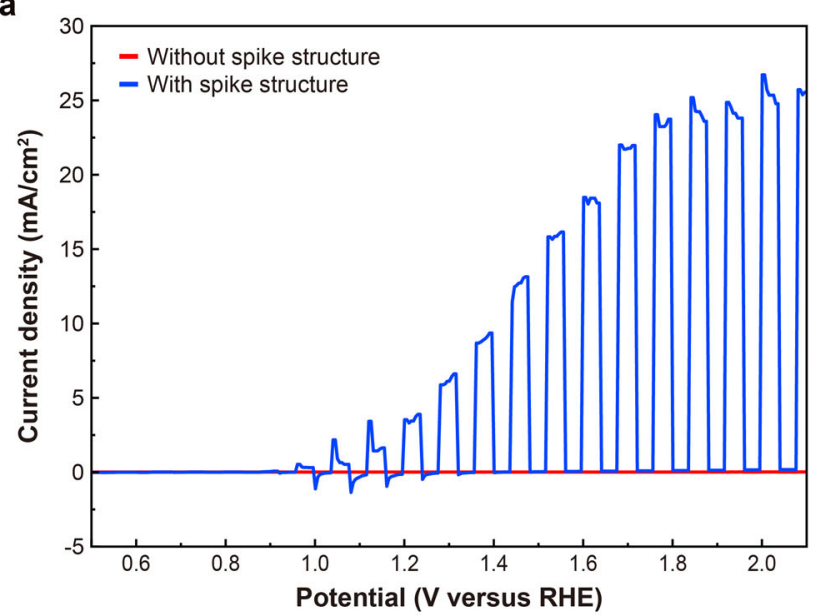

b

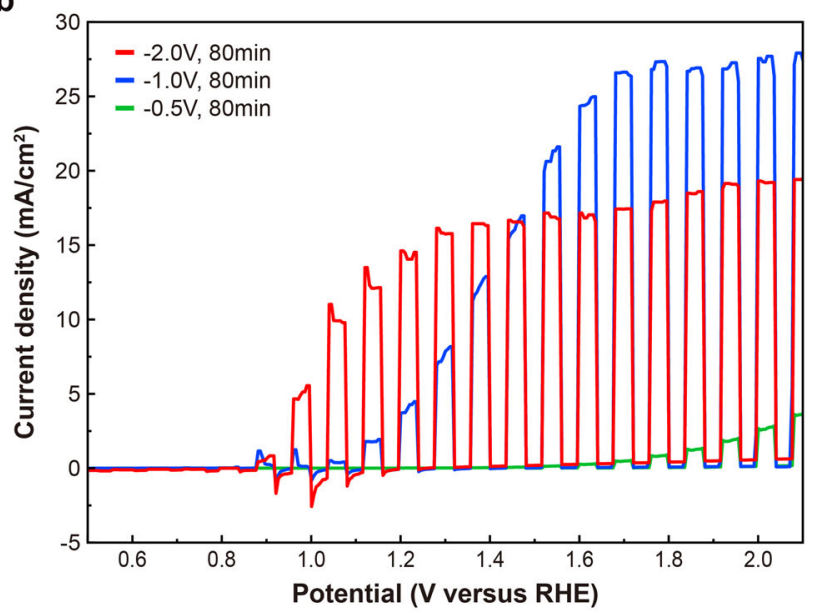

C

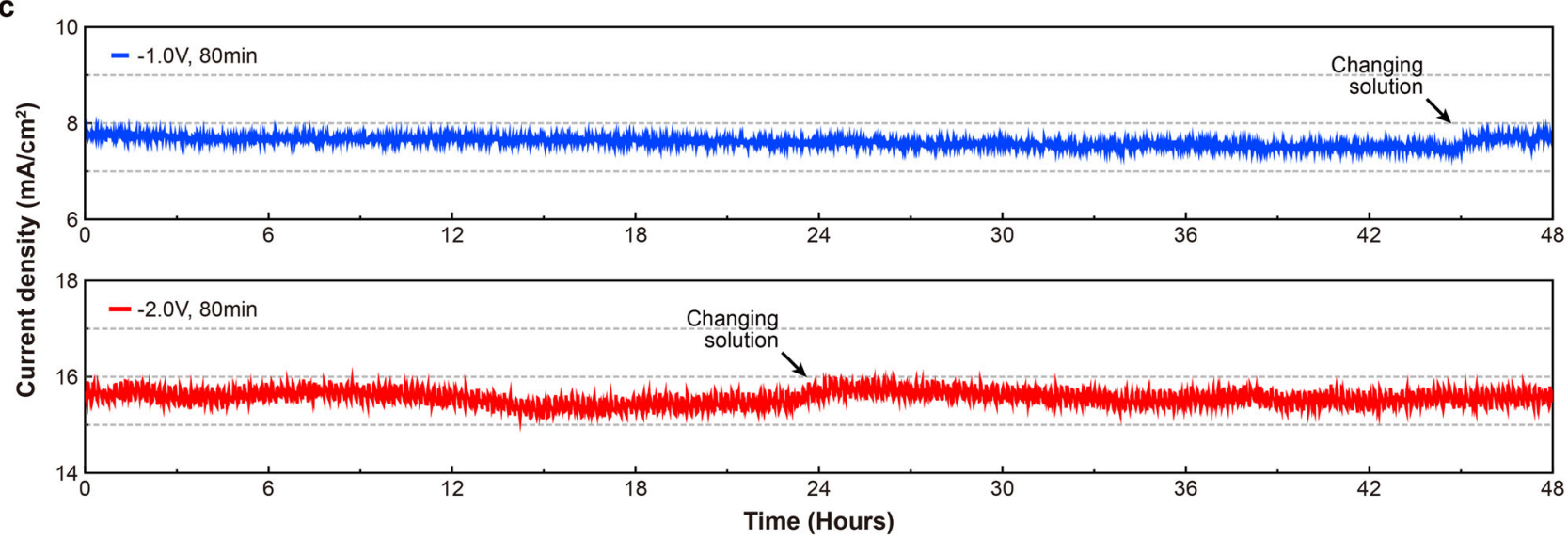

Fig. 4 PEC characterization for $\mathbf{N i} / \mathbf{9 0} \mathbf{~ n m ~ S i O} \mathbf{~}_{\mathbf{2}} / \mathbf{n}$-Si photoanodes. a LSV curves obtained in $1 \mathrm{M} \mathrm{KOH}$ solution with chopped AM1.5G illumination for Ni/ $90 \mathrm{~nm} \mathrm{SiO} / 2 / \mathrm{n}$-Si photoanodes with (blue) and without (red) Al spiking included in the fabrication process. b LSV curves for spiked Ni/90 nm SiO $/ 2$ - $\mathrm{Si}$ photoanodes with $\mathrm{Ni}$ electrodeposited for $80 \mathrm{~min}$ at $-0.5,-1.0$, and $-2.0 \mathrm{~V}$ applied bias. c $48 \mathrm{~h} \mathrm{CA}$ stability tests at $-1.3 \mathrm{~V}$ versus RHE in $1 \mathrm{M} \mathrm{KOH}$ solutions for spiked $\mathrm{Ni} / 90 \mathrm{~nm} \mathrm{SiO}_{2} / \mathrm{Si}$ photoanodes with $\mathrm{Ni}$ electrodeposited for $80 \mathrm{~min}$ at -1.0 and $-2.0 \mathrm{~V}$ applied bias.

islands penetrated through the $\mathrm{SiO}_{2}$ layer to the underlying $\mathrm{Si}$ surface (Supplementary Fig. 5). We refer to photoanodes fabricated in this manner, with $\mathrm{Ni}$ metal catalysts penetrating the $\mathrm{SiO}_{2}$ protective layer via voids created by the $\mathrm{Al}$ spiking and etching processes, as spiked $\mathrm{Ni} / \mathrm{SiO}_{2} / \mathrm{Si}$ photoanodes.

PEC performance for the $\mathrm{Ni} / \mathrm{SiO}_{2} / \mathrm{Si}$ photoanodes. PEC performance was measured for spiked $\mathrm{Ni} / \mathrm{SiO}_{2} / \mathrm{Si}$ photoanodes fabricated using various $\mathrm{Ni}$ electrodeposition processes in $1 \mathrm{M} \mathrm{KOH}$ $(\mathrm{pH}=14)$ aqueous solution with a standard three-electrode system under standard AM1.5G 1sun illumination. Figure 4a shows linear sweep voltammetry (LSV) measurements with chopped illumination for $\mathrm{Ni} / \mathrm{SiO}_{2} / \mathrm{Si}$ photoanodes fabricated with and without the $\mathrm{Al}$ thin-film reaction process. Both photoanodes were fabricated with the same Ni coverage on the surface. For the spiked structures, the Ni layer was deposited by electrodeposition at $-2.0 \mathrm{~V}$ applied bias for 60 min yielding $~ 75 \%$ surface coverage with electrodeposited Ni. For the photoanode fabricated without Al spiking, the Ni layer was deposited using e-beam evaporation with the same $75 \%$ coverage as the electrodeposited Ni layer using a lithographically defined pattern consisting of $60 \mu \mathrm{m}$ diameter dots in a square array with $60 \mu \mathrm{m}$ pitch. As shown in Fig. $4 \mathrm{a}$, the $\mathrm{Ni} / \mathrm{SiO}_{2} / \mathrm{Si}$ photoanode without spiking showed very low current density, under $10 \mu \mathrm{A} / \mathrm{cm}^{2}$. This current density is at the noiselimited detection limit of our measurement system, indicating that there is minimal tunneling of the photogenerated charges through the thick $\mathrm{SiO}_{2}$ layer. Clear OER activity was observed with the spiked structure, which showed a low onset potential of $1.0 \mathrm{~V}$ versus reversible hydrogen electrode (RHE) and a high saturation current density of $25 \mathrm{~mA} / \mathrm{cm}^{2}$. This result confirms that the spiked structure dramatically improves the performance in the aqueous solution of the $\mathrm{Ni} / \mathrm{SiO}_{2} / \mathrm{Si}$ photoanode by providing conductive paths through the $\mathrm{SiO}_{2}$ layer. All results reported below are for spiked $\mathrm{Ni} / \mathrm{SiO}_{2} / \mathrm{Si}$ photoanode structures fabricating using the $\mathrm{Al}$ thin-film reaction process.

Figure $4 \mathrm{~b}$ shows the PEC performance of spiked $\mathrm{Ni} / \mathrm{SiO}_{2} / \mathrm{Si}$ photoanodes for different electrodeposited $\mathrm{Ni}$ morphologies on the surface. We prepared three spiked $\mathrm{Ni} / \mathrm{SiO}_{2} / \mathrm{Si}$ photoanodes with different electrodeposition recipes. The measured $\mathrm{Ni}$ coverages of the photoanodes were $3.9 \%, 34.4 \%$, and $80.2 \%$ for $80 \mathrm{~min}$ of $\mathrm{Ni}$ electrodeposition at $-0.5,-1.0$, and $-2.0 \mathrm{~V}$ applied biases, respectively. The spiked $\mathrm{Ni} / \mathrm{SiO}_{2} / \mathrm{Si}$ photoanode with $3.9 \%$ $\mathrm{Ni}$ coverage showed poor PEC performance due to insufficient $\mathrm{Ni}$ coverage on the surface. The highest saturation photocurrent density $\left(27 \mathrm{~mA} / \mathrm{cm}^{2}\right)$ was observed for $34.4 \% \mathrm{Ni}$ coverage, achieved by $\mathrm{Ni}$ electrodeposition at $-1.0 \mathrm{~V}$ bias. For the spiked $\mathrm{Ni} / \mathrm{SiO}_{2} / \mathrm{Si}$ photoanode with $80.2 \% \mathrm{Ni}$ coverage, a lower saturation photocurrent density $\left(16 \mathrm{~mA} / \mathrm{cm}^{2}\right)$ was observed compared to the photoanode with $34.4 \%$ of $\mathrm{Ni}$ coverage, a reduction we attribute to blocking of incident light by the $\mathrm{Ni}$ layer. However, an enhancement in onset potential for OER was observed, from 1.1 to $0.9 \mathrm{~V}$ versus RHE, for $80.2 \%$ Ni coverage on 
the surface compared to that for $34.4 \%$. This result indicates that, unsurprisingly, the catalytic effect of $\mathrm{Ni}$ was improved with increasing Ni coverage, leading to lower onset potential. However, excessive $\mathrm{Ni}$ coverage limits light absorption in the underlying $\mathrm{Si}$ absorber, reducing the photocurrent density.

The corrosion resistance of the spiked $\mathrm{Ni} / \mathrm{SiO}_{2} / \mathrm{Si}$ photoanodes at high $\mathrm{pH}$ was assessed by chronoamperometry (CA). As shown in Fig. 4c, CA tests for spiked $\mathrm{Ni} / \mathrm{SiO}_{2} / \mathrm{Si}$ photoanodes with different $\mathrm{Ni}$ electrodepositions at -1.0 and $-2.0 \mathrm{~V}$ were performed in $1 \mathrm{M} \mathrm{KOH}(\mathrm{pH}=14)$ aqueous solution at $1.3 \mathrm{~V}$ versus $\mathrm{RHE}$ for $48 \mathrm{~h}$. Due to the $90 \mathrm{~nm}$ thick $\mathrm{SiO}_{2}$ layer and the high corrosion resistance of $\mathrm{Ni}$ for high $\mathrm{pH}$ solutions, both spiked $\mathrm{Ni} / \mathrm{SiO}_{2} / \mathrm{Si}$ photoanodes showed excellent stability over the entire $48 \mathrm{~h}$ measurement duration (Supplementary Fig. 7). Due to the higher rate of gas evolution for the photoanode with $\mathrm{Ni}$ electrodeposition at $-2.0 \mathrm{~V}$, more fluctuations in photocurrent density were observed during the stability test. A small decrease in photocurrent density was observed for both photoanodes during the stability test, since some of the produced $\mathrm{O}_{2}$ bubbles remain attached to the surface and suppress the OER reaction. After drying the surface using Ar dry gas and changing to a new $1 \mathrm{M} \mathrm{KOH}$ aqueous solution, the photocurrent density recovered to the initial values, indicating that there was no chemical corrosion on the surface.

Numerical analysis of photoanode potential distributions. The effects of localized contacts in the spiked $\mathrm{Ni} / \mathrm{SiO}_{2} / \mathrm{Si}$ photoanode were also analyzed computationally using a commercial numerical solver, COMSOL Multiphysics, to help explain the favorable onset potentials observed (Fig. 5 and Supplementary Fig. 8). Three different models were simulated, consisting of different $\mathrm{Ni} /$ $\mathrm{SiO}_{2} / \mathrm{Si}$ structures with metal back contacts (Fig. 5a). Models 1 and 2 were designed as typical MIS structures without metal spikes, with $\mathrm{SiO}_{2}$ thicknesses of 5 and $90 \mathrm{~nm}$, respectively. Model 3 had a similar structure to Model 2, but also included a cylindrical metal spike with a diameter of $60 \mathrm{~nm}$ and a Schottky contact between $\mathrm{Ni}$ and $\mathrm{Si}$ at the bottom of the spike. Figure $5 \mathrm{~b}, \mathrm{c}$ shows the simulated band structures and hole concentrations of Models 1, 2, and 3. The electrical behavior of Models 1 and 2 is readily explained by the MIS capacitor model ${ }^{36}$. The band structure of a typical MIS contact with a very thin insulating layer is nearly Schottky-like, as shown in Fig. 5b. Due to the high work function of $\mathrm{Ni}(5.0 \mathrm{eV})$ and small potential difference across the thin $\mathrm{SiO}_{2}$ layer, there is weak surface inversion at the Si surface and a favorable onset potential would be expected. With the increasing thickness of the $\mathrm{SiO}_{2}$ layer, even weaker surface inversion is observed with less band bending in the Si layer. Therefore, a lower concentration of holes accumulates at the Si surface for Model 2, which has a thicker $\mathrm{SiO}_{2}$ layer, causing decreased photovoltage ${ }^{36}$. As shown in Fig. 5c, two types of interfaces are present in Model 3 depending on radial distance $(\mathrm{R})$ from the spiked area: $\mathrm{Si} / \mathrm{Ni}$ at $R=0 \mathrm{~nm}$ and $\mathrm{Si} / \mathrm{SiO}_{2} / \mathrm{Ni}$ at $R=$ $200 \mathrm{~nm}$. For $R=200 \mathrm{~nm}$ in Model 3, the simulated band structure is almost same as for Model 2. In the case of $R=0 \mathrm{~nm}, \mathrm{Ni}$ is in direct contact with $\mathrm{Si}$, with an $0.67 \mathrm{eV}$ Schottky barrier, leading to stronger surface inversion and higher local hole concentration at the Si surface. Figure 5d shows the simulated conduction-band edge energy $\left(E_{\mathrm{C}}\right)$ profile as a function of the radial distance $(R)$ from the center of the spiked area and the depth below Si surface. The Si conduction-band edge energy decreases by $\sim 0.5 \mathrm{eV}$ as $R$ increases from 0 to $200 \mathrm{~nm}$, so that higher hole concentrations are present in the $\mathrm{Si} / \mathrm{SiO}_{2} / \mathrm{Ni}$ structures primarily near the spiked area. In the MIS photoanode with a localized spike structure, the localized high hole concentration on the Si surface is sufficient to lead to a photovoltage improvement of the photoanode compared to that expected for structures with no spiking.
Spiked $\mathrm{Ni} / \mathrm{SiO}_{2} / \mathrm{Si}$ photoanode with $\mathbf{p}^{+} \mathbf{n}-\mathrm{Si}$. To further improve the photoelectrochemical onset potential, we incorporated a $\mathrm{p}^{+} \mathrm{n}$ $\mathrm{Si}$ junction for the spiked $\mathrm{Ni} / \mathrm{SiO}_{2} / \mathrm{Si}$ photoanode. It has been reported that thin $\mathrm{p}^{+}$doping on the $\mathrm{n}$-Si surface improves the OER performance of MIS photoanodes due to the higher hole density at the Si surface ${ }^{36,37}$. The $\mathrm{p}^{+}$doping on the surface was performed by boron diffusion with an expected junction depth of $\sim 300 \mathrm{~nm}$, since a junction depth above $1 \mu \mathrm{m}$ is expected to increase interface recombination ${ }^{36}$ (Supplementary Fig. 9). Figure 6a shows LSV measurements with chopped illumination for spiked $\mathrm{Ni} / \mathrm{SiO}_{2} / \mathrm{Si}$ photoanodes fabricated using $\mathrm{p}^{+} \mathrm{n}-\mathrm{Si}$ and $\mathrm{n}-\mathrm{Si}$ substrates with similar Ni coverage on the surface $(\sim 35 \%)$. The spiked $\mathrm{Ni} / \mathrm{SiO}_{2} / \mathrm{p}^{+} \mathrm{n}$-Si photoanode showed enhanced OER performance compared to the spiked $\mathrm{Ni} / \mathrm{SiO}_{2} / \mathrm{n}$-Si photoanode, with a lower onset potential of $0.7 \mathrm{~V}$ versus RHE and a higher saturation current density of $32 \mathrm{~mA} / \mathrm{cm}^{2}$ (Supplementary Fig. 10). In addition, as shown in Fig. 6c, highly stable photocurrent density was observed in a CA measurement for the spiked $\mathrm{Ni}$ / $\mathrm{SiO}_{2} / \mathrm{p}^{+} \mathrm{n}$-Si photoanode in $1 \mathrm{M} \mathrm{KOH}$ aqueous solution at $1.3 \mathrm{~V}$ versus RHE, with a constant photocurrent density of 21-22 A/ $\mathrm{cm}^{2}$ maintained over the entire duration of a 7-days stability test. For the calculation of Faradaic efficiency, the evolved $\mathrm{H}_{2}$ and $\mathrm{O}_{2}$ gases were measured for the spiked $\mathrm{Ni} / \mathrm{SiO}_{2} / \mathrm{p}^{+} \mathrm{n}-\mathrm{Si}$ photoanode at $1.23 \mathrm{~V}$ versus RHE. The generation rates of $\mathrm{H}_{2}$ and $\mathrm{O}_{2}$ gases exhibited the expected stoichiometric ratio (2:1). The calculated Faradaic efficiency started at $72.7 \%$ and saturated near $86 \%$ at $20 \mathrm{~min}$, indicating good stability for the $120 \mathrm{~min}$ measurement (Fig. 6b). It has been reported that saturated faradaic efficiency of $\sim 85 \%$ is a typical value for OER due to limiting factors such as the back reaction of the dissolved oxygen ${ }^{38}$, oxidation of $\mathrm{Ni}$ catalysts $^{39}$, and facile electrolyte anion oxidation ${ }^{40}$.

The improvement in OER performance for the spiked $\mathrm{Ni} / \mathrm{SiO}_{2} /$ $\mathrm{p}^{+} \mathrm{n}$-Si photoanode was analyzed by simulating its band structure for a gaussian acceptor doping profile corresponding to a boron diffusion process from the surface with a junction depth of 300 $\mathrm{nm}$, referred to as Model 4 (Supplementary Fig. 11). Figure 6d shows the simulated band structures of Model 4 with $R=0 \mathrm{~nm}$ and $R=200 \mathrm{~nm}$. The spiked $(R=0 \mathrm{~nm})$ and non-spiked $(R=$ $200 \mathrm{~nm}$ ) areas in Model 4 showed almost the same band structures, since the $\mathrm{p}^{+}-\mathrm{Si}$ and $\mathrm{Ni}$ form an Ohmic contact and band bending in the $\mathrm{Si}$ is dominated by the $\mathrm{p}^{+} \mathrm{n}$ junction. The $\mathrm{p}^{+}$ doping at the $\mathrm{n}$-Si surface enables a higher hole density to accumulate at the Si surface, as shown in Fig. 6e, leading to improved onset potential compared to the spiked $\mathrm{Ni} / \mathrm{SiO}_{2} / \mathrm{n}-\mathrm{Si}$ photoanode.

\section{Conclusion}

In summary, we have demonstrated a general method for lowcost, lithography-free, and scalable fabrication of Si-based MIS photoanodes by employing an $\mathrm{Al}$ thin-film reaction process combined with $\mathrm{Ni}$ catalyst electrodeposition. This approach allows a thick $\mathrm{SiO}_{2}$ insulator $(90 \mathrm{~nm})$ to be employed, which provides antireflection functionality on $\mathrm{Si}$ and high long-term stability in alkaline solutions. Optimization of the Al thin-film reaction process to create a suitable density of openings in the $\mathrm{SiO}_{2}$ layer, and of the $\mathrm{Ni}$ electrodeposition process to achieve optimal Ni surface coverage, leads to favorable onset potentials and high photocurrent densities. The enhancement in OER performance was analyzed by PEC measurements and numerical simulations using MIS Schottky contact models. In PEC measurements, the optimized Si-based MIS photoanode with a buried $\mathrm{p}^{+} \mathrm{n}-\mathrm{Si}$ junction showed low onset potential and high saturation photocurrent density around $0.7 \mathrm{~V}$ versus RHE and $32 \mathrm{~mA} / \mathrm{cm}^{2}$, respectively. Furthermore, the high photocurrent density was maintained for the entirety of a 7-days stability test in a $1 \mathrm{M} \mathrm{KOH}$ 
a

Model 1

$5 \mathrm{~nm} \mathrm{SiO}_{2}$ without spike

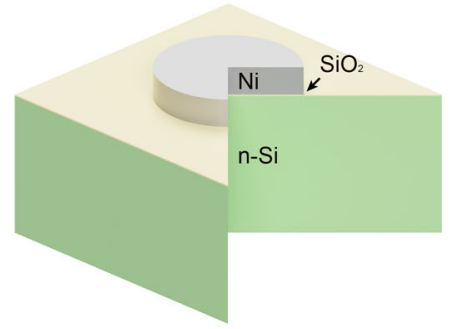

b

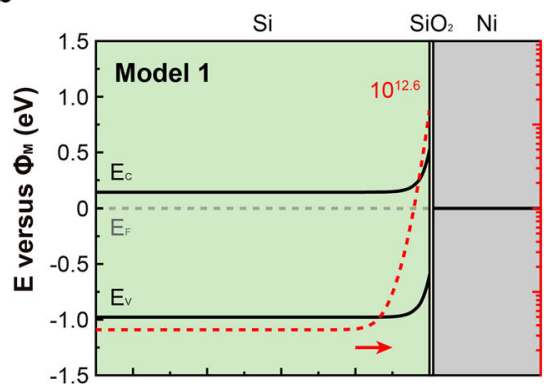

C

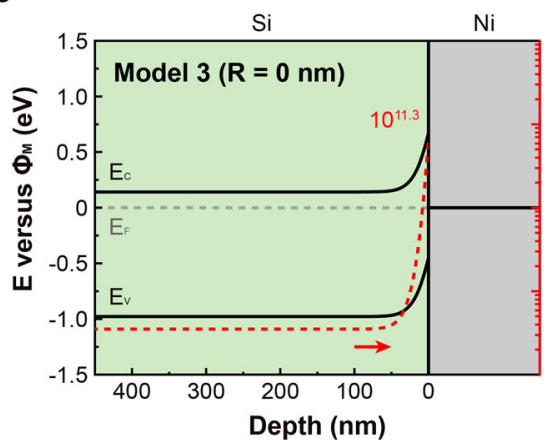

Model 2

$90 \mathrm{~nm} \mathrm{SiO}$ without spike
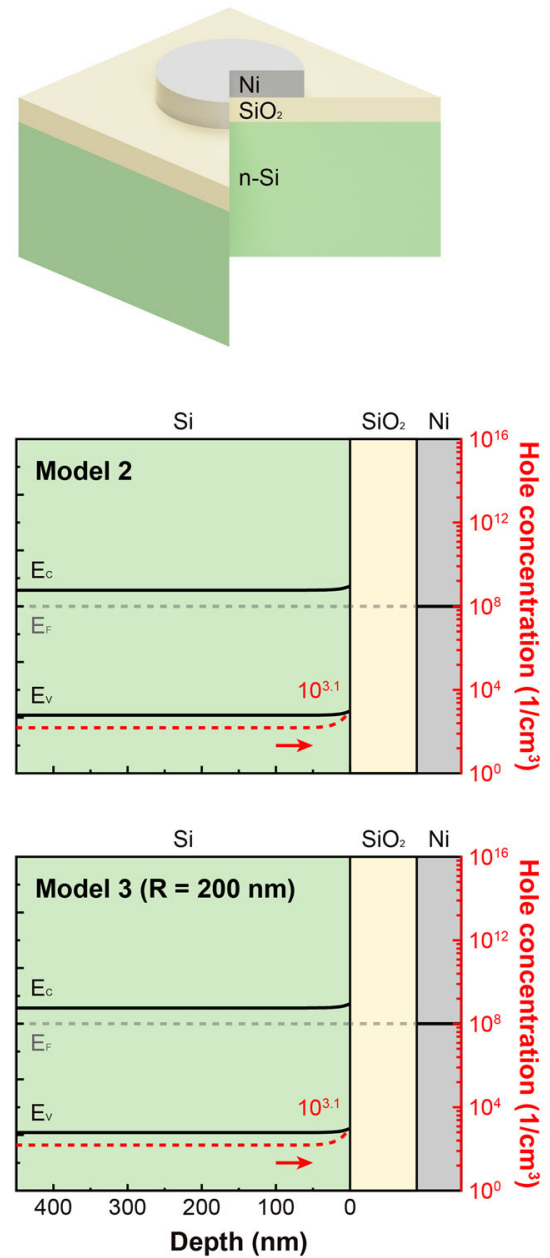

Model 3

$90 \mathrm{~nm} \mathrm{SiO}_{2}$ with spike

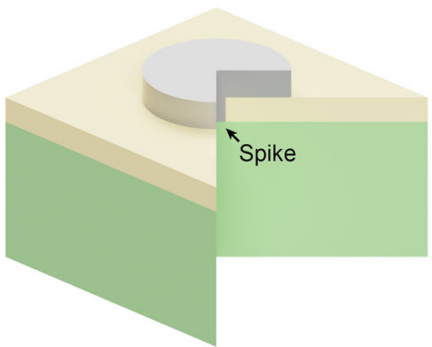

d

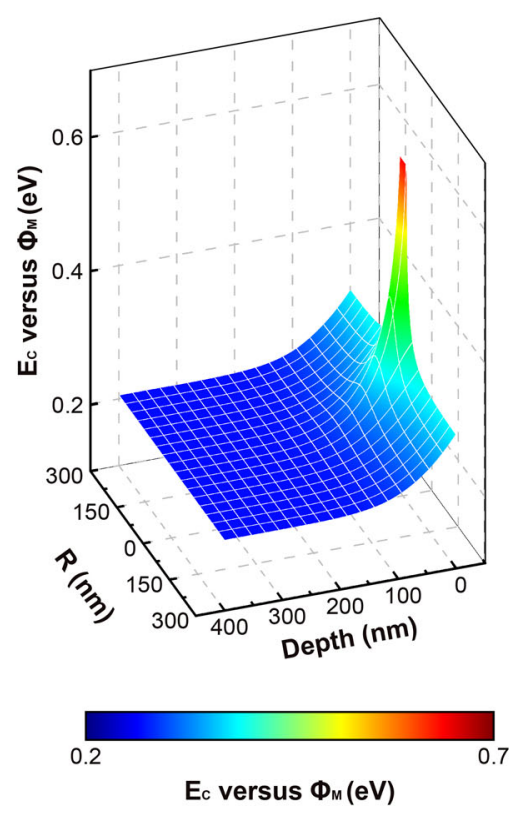

Fig. 5 Simulations showing potential distributions for different models. a Schematic illustrations of 3D simulation geometries for MIS photoanodes: Ni/5 $\mathrm{nm} \mathrm{SiO}_{2} / \mathrm{n}$-Si without spike for Model 1, Ni/90 nm SiO $2 / n-S i$ without spike for Model 2, and Ni/90 nm SiO $/ \mathrm{n}-\mathrm{Si}$ with a $60 \mathrm{~nm}$ diameter spike for Model 3. b Simulated band-edge energy diagrams and hole concentrations at the interface area for Models 1 and 2 . c Simulated band-edge energy diagrams and hole concentrations for Model 3, at radial distances from the center of the spike, $R$, of 0 and 200 nm. d Simulated conduction-band-edge energy ( $E_{C}$ ) profile near the spiked area in Model 3.

aqueous solution. These results demonstrate a low-cost, highly scalable approach for the fabrication of efficient and very stable photoanodes that is suitable for large-scale commercial fabrication and readily adaptable to a variety of catalyst, insulator, and semiconductor materials.

\section{Methods}

Fabrication of $\mathbf{N i} / \mathrm{SiO}_{\mathbf{2}} / \mathbf{n}$-Si photoanodes with localized spike structures. 4 inch n-type (100) c-Si wafers (thickness $t \sim 550 \mu \mathrm{m}$ and resistivity $\rho=0.3-0.5 \Omega$ $\mathrm{cm}$ ) were used for the fabrication of photoanodes. Each wafer was cleaved into $2 \times$ $2 \mathrm{~cm}^{2}$ samples and cleaned with piranha solution $\left(5: 1: 1 \mathrm{H}_{2} \mathrm{O}: \mathrm{H}_{2} \mathrm{SO}_{4}: \mathrm{H}_{2} \mathrm{O}_{2}\right)$. Cleaned Si substrates were dipped into a 5\% HF aqueous solution for $1 \mathrm{~min}$ to remove the native oxide. For the back contact, $5 \mathrm{~nm} \mathrm{Cr}$ and $100 \mathrm{~nm}$ Au were deposited on the backside of the $\mathrm{Si}$ substrates by e-beam evaporation. High-quality $\mathrm{SiO}_{2}$ films were thermally grown on the front side of each $\mathrm{Si}$ wafer using an oxidation furnace (MRL $8^{\prime}$ furnace, Sandvik Thermal Process Inc.) at $950^{\circ} \mathrm{C}$ in dry $\mathrm{O}_{2}$ ambient. In this work, all photoanodes were fabricated with $90 \mathrm{~nm} \mathrm{SiO}$ layers. An Al-Si layer with $1 \% \mathrm{Si}$ content was deposited onto the $\mathrm{SiO}_{2} / \mathrm{Si}$ surface by DC magnetron sputtering (UNIVEX 450B) under $1 \times 10^{-6}$ Torr of base pressure. The use of $\mathrm{Si}$-doped $\mathrm{Al}$ suppresses penetration of the $\mathrm{Al}$ metallization into the $\mathrm{Si}$ layers. For the formation of localized $\mathrm{Al}$ spikes through the $\mathrm{SiO}_{2}$ layer, $\mathrm{Al} / \mathrm{SiO}_{2} / \mathrm{Si}$ substrates were annealed at temperatures of $450-600{ }^{\circ} \mathrm{C}$ and durations of up to $24 \mathrm{~h}$ in a vacuum chamber. To replace the top $\mathrm{Al}$ layer with the $\mathrm{Ni}$ catalyst, $\mathrm{Al}$ was etched using a $10 \% \mathrm{H}_{3} \mathrm{PO}_{4}$ aqueous solution for $6 \mathrm{~h}$. After Al etching, the surface was rinsed by DI water and dried under $\mathrm{N}_{2}$ flow. The Ni catalyst was deposited by electrodeposition. The Ni plating solution consisted of a $0.1 \mathrm{M}$ boric acid and $0.1 \mathrm{M}$ $\mathrm{NiCl}_{2}$ aqueous solution. During electrodeposition, only the $\mathrm{SiO}_{2} / \mathrm{Si}$ surface from which $\mathrm{Al}$ was etched was exposed to the Ni plating solution. The working electrode was connected to the back contact and both the Pt counter electrode and $\mathrm{Ag} / \mathrm{AgCl}$ $(3 \mathrm{M} \mathrm{KCl})$ reference electrode were dipped in the Ni plating solution. The $\mathrm{Ni}$ electrodeposition was performed with different applied bias voltages $(-0.5,-1.0$, and $-2.0 \mathrm{~V}$ versus $\mathrm{Ag} / \mathrm{AgCl}$ ) with deposition times ranging from 0 to $120 \mathrm{~min}$. The resulting spiked $\mathrm{Ni} / \mathrm{SiO}_{2} / \mathrm{Si}$ MIS photoanodes were rinsed in DI water and dried naturally under ambient conditions.

Fabrication of $\mathbf{N i} / \mathrm{SiO}_{2} / \mathbf{p}^{+} \mathbf{n}-\mathbf{S i}$ photoanodes. $\mathrm{p}^{+}$doping on the surface of 4 inch n-type (100) c-Si wafers was performed by annealing n-Si substrates with a boron solid-state source (BoronPlus ${ }^{\mathrm{TM}}$ ) at $950{ }^{\circ} \mathrm{C}$ for $70 \mathrm{~min}$ with an $\mathrm{N}_{2}$ flow rate of 3.5 $\mathrm{L} / \mathrm{min}$. These conditions were designed to yield a Gaussian boron diffusion profile with $300 \mathrm{~nm}$ junction depth. The $5 \mathrm{nmCr} / 100 \mathrm{nmAu}$ back contact, thermally grown $90 \mathrm{~nm} \mathrm{SiO}$ layer, and $100 \mathrm{~nm}$ Al layer were fabricated using the same methods as for the fabrication of $\mathrm{Ni} / \mathrm{SiO}_{2} / \mathrm{n}$-Si photoanodes, as described above. After the fabrication of the $\mathrm{Al} / \mathrm{SiO}_{2} / \mathrm{p}^{+} \mathrm{n}$-Si structure, $\mathrm{Al}$ spiking was induced by annealing at $550{ }^{\circ} \mathrm{C}$ for $24 \mathrm{~h}$ in a vacuum chamber, followed by Al etching. Subsequently, 35\% $\mathrm{Ni}$ coverage was obtained by electrodeposition at $-3.0 \mathrm{~V}$ versus $\mathrm{Ag} / \mathrm{AgCl}$ for $30 \mathrm{~min}$.

Measurements of resistance change after Al spiking. To evaluate the resistance change after the $\mathrm{Al}$ spiking anneal, dual-sided $\mathrm{Al} / \mathrm{SiO}_{2} / \mathrm{Si} / \mathrm{SiO}_{2} / \mathrm{Al}$ MIS samples 
a

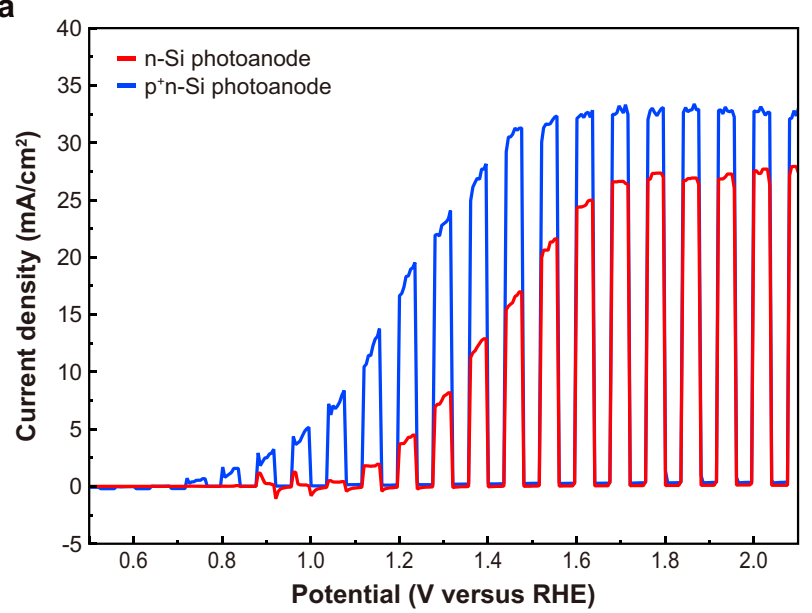

C

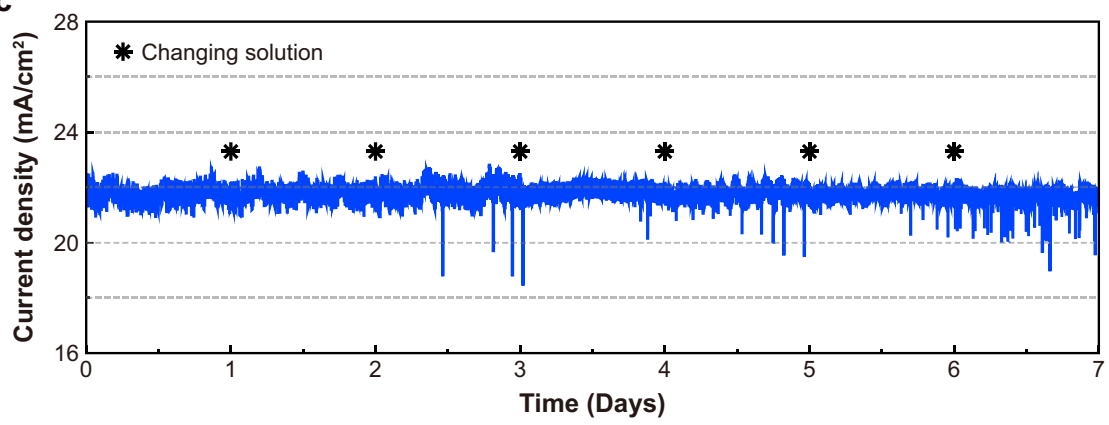

d

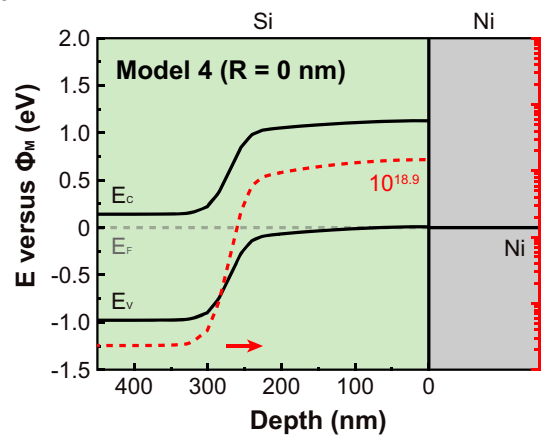

b

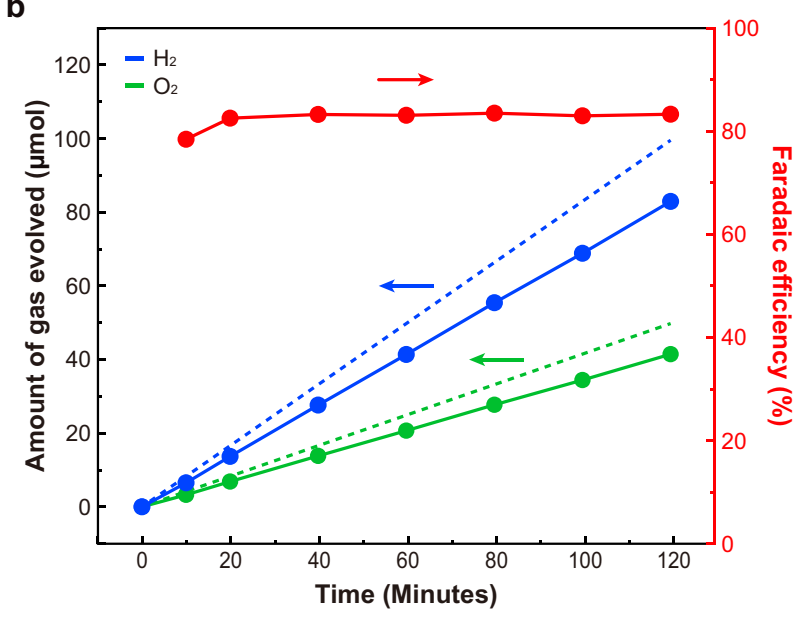

e

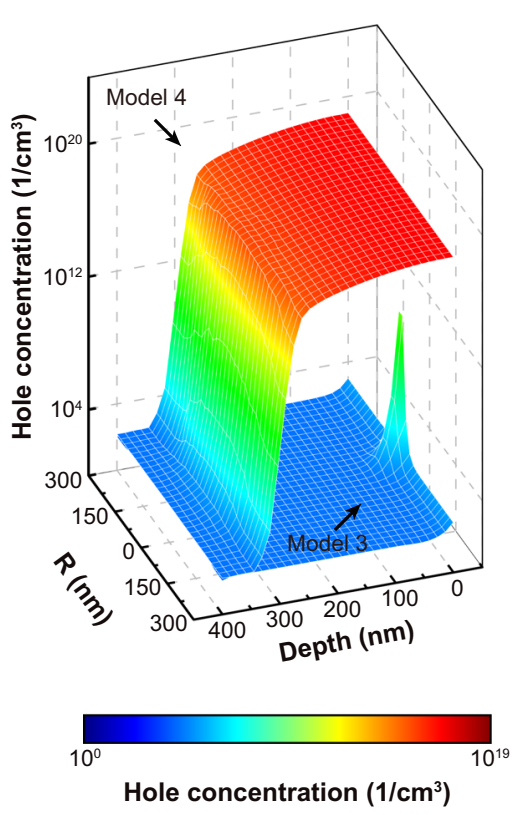

Fig. 6 PEC characterization and simulations for the spiked $\mathbf{N i} / \mathbf{S i O}_{\mathbf{2}} / \mathbf{p}^{+} \mathbf{n}-\mathrm{Si}$ photoanode. a LSV curves obtained in $1 \mathrm{M} \mathrm{KOH}$ solution with chopped AM1.5G illumination for spiked $\mathrm{Ni} / 90 \mathrm{~nm} \mathrm{SiO} / 2 / \mathrm{n}-\mathrm{Si}$ (red) and spiked $\mathrm{Ni} / 90 \mathrm{~nm} \mathrm{SiO} / 2 / \mathrm{p}^{+} \mathrm{n}-\mathrm{Si}$ (blue) photoanodes. b Ideal (dotted lines) and measured (solid lines and symbols) evolution of $\mathrm{H}_{2}$ and $\mathrm{O}_{2}$ gases during OER activity at $1.23 \mathrm{~V}$ versus RHE for 120 min. The Faradaic efficiency was calculated for $\mathrm{O}_{2}$ gas evolution. c 7-days CA stability test at $-1.3 \mathrm{~V}$ versus RHE in $1 \mathrm{M} \mathrm{KOH}$ solution. $\mathbf{d}$ Simulated band diagrams and hole concentrations for Model 4 for $R=$ $0 \mathrm{~nm}$ and $R=200 \mathrm{~nm}$. e Simulated hole concentration near the spiked area for Models 3 and 4.

were prepared. First, 20,30, 40, and $90 \mathrm{~nm} \mathrm{SiO}_{2}$ layers were grown on both sides of $2 \times 2 \mathrm{~cm}^{2}$ double-side polished $n$-type $S i$ substrates using a thermal oxidation furnace at $950{ }^{\circ} \mathrm{C}$ in dry $\mathrm{O}_{2}$ ambient. Then, $100 \mathrm{~nm} \mathrm{Al}$ films were deposited on both sides of the resulting $\mathrm{SiO}_{2} / \mathrm{Si}_{/} / \mathrm{SiO}_{2}$ substrates using DC magnetron sputtering. To induce localized $\mathrm{Al}$ spiking, the $\mathrm{Al} / \mathrm{SiO}_{2} / \mathrm{Si} / \mathrm{SiO}_{2} / \mathrm{Al}$ samples were annealed at 450 , 500,550 , and $650^{\circ} \mathrm{C}$ for annealing times ranging from 0 to $24 \mathrm{~h}$. Three $\mathrm{Al} / \mathrm{SiO}_{2} / \mathrm{Si} /$ $\mathrm{SiO}_{2} / \mathrm{Al}$ samples were prepared for each annealing recipe for the measurements. Before and after each annealing process, the top and bottom Al layers were connected to anode and cathode, respectively, and linear sweep voltammetry (LSV) was performed for evaluating the resistance between the top and bottom of each sample.

PEC measurements. All PEC measurements were performed using a $\mathrm{CHI} 760 \mathrm{E}$ electrochemical workstation (CH Instruments, Austin, United States) with a standard three-electrode electrochemical cell consisting of Pt wire as a counter electrode and an $\mathrm{Ag} / \mathrm{AgCl}$ reference electrode. The alkaline solution $(\mathrm{pH}=14)$ for the OER characterization consisted of a $1 \mathrm{M} \mathrm{KOH}$ aqueous solution (semiconductor grade, Sigma-Aldrich, $99.99 \%$ trace metal basis). The measured potentials versus $\mathrm{Ag} / \mathrm{AgCl}$ were converted to potential versus reversible hydrogen electrode (RHE) using the following equation:

$$
E_{\mathrm{RHE}}=E_{\mathrm{Ag} / \mathrm{AgCl}}+0.197 \mathrm{~V}+0.059 \times \mathrm{pH}
$$

The LSV and chronoamperometry (CA) measurements were carried out for the photoanodes under $100 \mathrm{~mW} / \mathrm{cm}^{2}$ light illumination using a Xenon arc lamp (66475, Newport) with an AM1.5G optical filter for characterization of OER efficiency and long-term stability tests. To evaluate the energy conversion of photoanode, the applied bias photon-to-current efficiency (ABPE) was calculated using the following equation ${ }^{41}$.

$$
\mathrm{ABPE}=\frac{P_{\text {out }}-P_{\text {in }}}{P_{\text {light }}}=\frac{J_{\text {ph }}\left(V_{\text {redox }}-V_{\text {bias }}\right)}{P_{\text {light }}}
$$

where $V_{\text {redox }}$ is the redox potential for water splitting, $V_{\text {bias }}$ refers to the potential difference between the working and counter electrodes, $P_{\text {light }}$ is the light intensity, and $J_{\mathrm{ph}}$ is the measured photocurrent density. The $\mathrm{H}_{2}$ and $\mathrm{O}_{2}$ gas evolution were measured by $\mathrm{H}_{2}$ and $\mathrm{O}_{2}$ microsensors connected to a picoammeter (Unisense A/S, Denmark), respectively, in $1 \mathrm{M} \mathrm{KOH}$ solution at $1.23 \mathrm{~V}$ versus RHE under 
illumination. The faradaic efficiency (FE) of photoanode was calculated using the following equation ${ }^{41}$ :

$$
\mathrm{FE}=\frac{\text { Measure dgas evloution }}{\text { Theoretical gas evolution }}=\frac{\text { Measured } \mathrm{O}_{2} \text { evolution }}{\left(\frac{J_{\text {photo }} \times A \times T}{e} / 4\right) / N_{\mathrm{A}}} \times 100 \%
$$

where $J_{\text {photo }}$ is the photocurrent density $\left(\mathrm{A} / \mathrm{cm}^{2}\right), A$ is the illumination area $\left(\mathrm{cm}^{2}\right)$, $T$ is the measurement time (sec), $e$ is the charge magnitude of an electron $(1.602 \times$ $\left.10^{-19} \mathrm{C}\right)$, and $N_{\mathrm{A}}$ is Avogadro's constant $\left(6.02 \times 10^{23} \mathrm{~mol}^{-1}\right)$.

Characterization. The optical reflectance of the $\mathrm{Ni} / \mathrm{SiO}_{2} / \mathrm{Si}$ substrate was measured using a single grating monochromator optronics laboratory platform (OL 750). The surface and cross-sectional morphologies of spiked $\mathrm{SiO}_{2}$ and electrodeposited $\mathrm{Ni}$ samples were characterized using field emission scanning electron microscopy (Zeiss, USA). The elements on the surface were analyzed using energy-dispersive X-ray spectroscopy (Bruker Quantax EDS for SEM). For analyzing the surface morphology, the surface was scanned in tapping mode using an atomic force microscope (AIST-NT Omegascope). To evaluate the Ni electrodeposited surface, the diameters and surface coverages of voids and electrodeposited Ni nano-islands were calculated using the "Image J" platform. The numerical simulations for the photoanodes were performed using the semiconductor module of a commercial numerical finite-element solver (COMSOL Multiphysics).

\section{Data availability}

Data supporting the findings of this study are available within the article and its Supplementary Information files. Additional data are available from the authors upon reasonable request.

Received: 5 January 2021; Accepted: 7 June 2021;

Published online: 25 June 2021

\section{References}

1. Warren, S. C. et al. Identifying champion nanostructures for solar watersplitting. Nat. Mater. 12, 842-849 (2013).

2. Chen, X., Liu, L., Yu, P. Y. \& Mao, S. S. Increasing solar absorption for photocatalysis with black hydrogenated titanium dioxide nanocrystals. Science 331, 746-750 (2011).

3. Paracchino, A., Laporte, V., Sivula, K., Grätzel, M. \& Thimsen, E. Highly active oxide photocathode for photoelectrochemical water reduction. Nat. Mater. 10, 456-461 (2011).

4. Liao, L. et al. Efficient solar water-splitting using a nanocrystalline $\mathrm{CoO}$ photocatalyst. Nat. Nanotechnol. 9, 69-73 (2014).

5. Karjule, N., Barrio, J., Xing, L., Volokh, M. \& Shalom, M. Highly efficient polymeric carbon nitride photoanode with excellent electron diffusion length and hole extraction properties. Nano Lett. 20, 4618-4624 (2020).

6. Liu, G. et al. Enabling an integrated tantalum nitride photoanode to approach the theoretical photocurrent limit for solar water splitting. Energy Environ. Sci. 9, 1327-1334 (2016).

7. Zhou, W. et al. $5.1 \%$ efficiency of Si photoanodes for photoelectrochemical water splitting catalyzed by porous $\mathrm{NiFe}$ (oxy)hydroxide converted from $\mathrm{NiFe}$ oxysulfide. Chem. Commun. 55, 12627-12630 (2019).

8. Ji, L. et al. A silicon-based photocathode for water reduction with an epitaxial SrTiO3 protection layer and a nanostructured catalyst. Nat. Nanotechnol. 10, 84-90 (2015).

9. Laskowski, F. A. L. et al. Nanoscale semiconductor/catalyst interfaces in photoelectrochemistry. Nat. Mater. 19, 69-76 (2020).

10. Ji, L. et al. Localized dielectric breakdown and antireflection coating in metaloxide-semiconductor photoelectrodes. Nat. Mater. 16, 127-131 (2017).

11. Loget, G., Fabre, B., Fryars, S., Mériadec, C. \& Ababou-Girard, S. Dispersed Ni nanoparticles stabilize silicon photoanodes for efficient and inexpensive sunlight-assisted water oxidation. ACS Energy Lett. 2, 569-573 (2017).

12. Zhao, J., Gill, T. M. \& Zheng, X. Enabling silicon photoanodes for efficient solar water splitting by electroless-deposited nickel. Nano Res. 11, 3499-3508 (2018).

13. Chuang, C.-H., Lai, Y.-Y., Hou, C.-H. \& Cheng, Y.-J. Annealed polycrystalline $\mathrm{TiO} 2$ interlayer of the $\mathrm{n}-\mathrm{Si} / \mathrm{TiO} 2 / \mathrm{Ni}$ photoanode for efficient photoelectrochemical water splitting. ACS Appl. Energy Mater. 3, 3902-3908 (2020).

14. Loget, G. et al. Tailoring the photoelectrochemistry of catalytic metalinsulator-semiconductor (MIS) photoanodes by a dissolution method. Nat. Commun. 10, 3522 (2019).

15. Hill, J. C., Landers, A. T. \& Switzer, J. A. An electrodeposited inhomogeneous metal-insulator-semiconductor junction for efficient photoelectrochemical water oxidation. Nat. Mater. 14, 1150-1155 (2015).
16. Digdaya, I. A., Adhyaksa, G. W. P., Trześniewski, B. J., Garnett, E. C. \& Smith, W A. Interfacial engineering of metal-insulator-semiconductor junctions for efficient and stable photoelectrochemical water oxidation. Nat. Commun. 8, 15968 (2017).

17. Oh, K., de Sagazan, O., Léon, C., Le Gall, S. \& Loget, G. Custom plating of nanoscale semiconductor/catalyst junctions for photoelectrochemical water splitting. Nanoscale 13, 1997-2004 (2021).

18. Kang, D. et al. Printed assemblies of GaAs photoelectrodes with decoupled optical and reactive interfaces for unassisted solar water splitting. Nat. Energy 2, 17043 (2017).

19. dos Santos, W. S. et al. Innovative multifunctional hybrid photoelectrode design based on a ternary heterojunction with super-enhanced efficiency for artificial photosynthesis. Sci. Rep. 10, 10669 (2020).

20. Lim, H. et al. High performance III-V photoelectrodes for solar water splitting via synergistically tailored structure and stoichiometry. Nat. Commun. 10, 3388 (2019)

21. Mishra, A. et al. Graphitic carbon nitride (g-C3N4)-based metal-free photocatalysts for water splitting: a review. Carbon 149, 693-721 (2019).

22. Wang, W., Xu, M., Xu, X., Zhou, W. \& Shao, Z. Perovskite oxide based electrodes for high-performance photoelectrochemical water splitting. Angew. Chem. Int. Ed. 59, 136-152 (2020).

23. Kenney, M. J. et al. High-performance silicon photoanodes passivated with ultrathin nickel films for water oxidation. Science 342, 836-840 (2013).

24. Cai, Q., Hong, W., Jian, C. \& Liu, W. Ultrafast hot ion-exchange triggered electrocatalyst modification and interface engineering on silicon photoanodes. Nano Energy 70, 104485 (2020).

25. Chen, C., Lu, Y., Fan, R. \& Shen, M. Integration of oxygen-vacancy-rich NiFelayered double hydroxide onto silicon as photoanode for enhanced photoelectrochemical water oxidation. ChemSusChem 13, 3893-3900 (2020).

26. $\mathrm{Li}, \mathrm{F}$. et al. Electroless plating of $\mathrm{NiFeP}$ alloy on the surface of silicon photoanode for efficient photoelectrochemical water oxidation. ACS Appl. Mater. Interfaces 12, 11479-11488 (2020).

27. Scheuermann, A. G. et al. Titanium oxide crystallization and interface defect passivation for high performance insulator-protected schottky junction MIS photoanodes. ACS Appl. Mater. Interfaces 8, 14596-14603 (2016).

28. Liu, B. et al. Bifacial passivation of $\mathrm{n}$-silicon metal-insulator-semiconductor photoelectrodes for efficient oxygen and hydrogen evolution reactions. Energy Environ. Sci. 13, 221-228 (2020).

29. Kumar, P. et al. Quantum dot activated indium gallium nitride on silicon as photoanode for solar hydrogen generation. Commun. Chem. 2, 4 (2019).

30. Maity, N. P., Maity, R. \& Baishya, S. Voltage and oxide thickness dependent tunneling current density and tunnel resistivity model: Application to high- $\mathrm{k}$ material HfO2 based MOS devices. Superlattices Microstructures 111, 628-641 (2017).

31. Shan, C. X., Hou, X. \& Choy, K.-L. Corrosion resistance of TiO2 films grown on stainless steel by atomic layer deposition. Surf. Coat. Technol. 202, 2399-2402 (2008).

32. Zhou, X. et al. $570 \mathrm{mV}$ photovoltage, stabilized n-Si/CoOx heterojunction photoanodes fabricated using atomic layer deposition. Energy Environ. Sci. 9, 892-897 (2016).

33. Bierhals, A., Aberle, A. G. \& Hezel, R. Improved understanding of thermally activated structural changes in $\mathrm{Al} / \mathrm{SiOx} / \mathrm{p}$-Si tunnel diodes by means of infrared spectroscopy. J. Appl. Phys. 83, 1371-1378 (1998).

34. Ho, A. W. Y. \& Wenham, S. R. Buried contact solar cells with innovative rear localised contacts. Prog. Photovoltaics 12, 297-308 (2004).

35. Godfrey, R. B. \& Green, M. A. High-temperature lifetesting of $\mathrm{Al} / \mathrm{SiOx} / \mathrm{p}-\mathrm{Si}$ contacts for MIS solar cells. Appl. Phys. Lett. 34, 860-861 (1979).

36. Scheuermann, A. G. et al. Design principles for maximizing photovoltage in metal-oxide-protected water-splitting photoanodes. Nat. Mater. 15, 99-105 (2016).

37. Green, M. A. \& Blakers, A. W. Advantages of metal-insulator-semiconductor structures for silicon solar cells. Sol. Cells 8, 3-16 (1983).

38. Pihosh, Y. et al. Photocatalytic generation of hydrogen by core-shell WO3/ BiVO4 nanorods with ultimate water splitting efficiency. Sci. Rep. 5, 11141 (2015).

39. Görlin, M. et al. Oxygen evolution reaction dynamics, faradaic charge efficiency, and the active metal redox states of $\mathrm{Ni}-\mathrm{Fe}$ oxide water splitting electrocatalysts. J. Am. Chem. Soc. 138, 5603-5614 (2016).

40. Mi, Q., Zhanaidarova, A., Brunschwig, B. S., Gray, H. B. \& Lewis, N. S. A quantitative assessment of the competition between water and anion oxidation at WO3 photoanodes in acidic aqueous electrolytes. Energy Environ. Sci. 5, 5694-5700 (2012)

41. Jiang, C., Moniz, S. J. A., Wang, A., Zhang, T. \& Tang, J. Photoelectrochemical devices for solar water splitting - materials and challenges. Chem. Soc. Rev. 46, 4645-4660 (2017)

\section{Acknowledgements}

Part of this work was supported by the National Science Foundation (CBET-1702944). This research was partially supported by the National Science Foundation through the 
Center for Dynamics and Control of Materials: an NSF MRSEC under Cooperative Agreement No. DMR-1720595. This work was performed in part at the University of Texas Microelectronics Research Center, a member of the National Nanotechnology Coordinated Infrastructure (NNCI), which is supported by the National Science Foundation (ECCS-2025227).

\section{Author contributions}

E.T.Y. conceived of the basic concept and approach, and S.L. and L.J. designed and performed the principal experiments. S.L. performed the reported device fabrication, measurements, and numerical simulations. A.C.D.P. performed the AFM measurements. S.L. and E.T.Y. wrote the manuscript, and all authors discussed the results and commented on the manuscript.

\section{Competing interests}

The authors and the University of Texas at Austin have submitted a provisional patent application covering aspects of this work.

\section{Additional information}

Supplementary information The online version contains supplementary material available at https://doi.org/10.1038/s41467-021-24229-y.

Correspondence and requests for materials should be addressed to L.J. or E.T.Y.
Peer review information Nature Communications thanks Han Gardeniers and the other, anonymous, reviewer(s) for their contribution to the peer review of this work.

Reprints and permission information is available at http://www.nature.com/reprints

Publisher's note Springer Nature remains neutral with regard to jurisdictional claims in published maps and institutional affiliations.

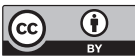

Open Access This article is licensed under a Creative Commons Attribution 4.0 International License, which permits use, sharing, adaptation, distribution and reproduction in any medium or format, as long as you give appropriate credit to the original author(s) and the source, provide a link to the Creative Commons license, and indicate if changes were made. The images or other third party material in this article are included in the article's Creative Commons license, unless indicated otherwise in a credit line to the material. If material is not included in the article's Creative Commons license and your intended use is not permitted by statutory regulation or exceeds the permitted use, you will need to obtain permission directly from the copyright holder. To view a copy of this license, visit http://creativecommons.org/ licenses/by/4.0/.

(C) The Author(s) 2021 